\section{DIACRONIE}

\section{Diacronie}

Studi di Storia Contemporanea

$N^{\circ} 7,3 \mid 2011$

«Spagna Anno Zero»: la guerra come soluzione

\title{
Julio Ponce Alberca, Gibraltar y la Guerra Civil Española. Una neutralidad singular
}

\section{Rodrigo González Martín}

\section{(2) OpenEdition}

Journals

\section{Edición electrónica}

URL: http://journals.openedition.org/diacronie/3152

DOI: $10.4000 /$ diacronie.3152

ISSN: 2038-0925

\section{Editor}

Association culturelle Diacronie

Referencia electrónica

Rodrigo González Martín, « Julio Ponce Alberca, Gibraltar y la Guerra Civil Española. Una neutralidad singular », Diacronie [En línea], № 7, 3 | 2011, documento 25, Puesto en línea el 29 julio 2011,

consultado el 22 septiembre 2020. URL : http://journals.openedition.org/diacronie/3152 ; DOI : https://doi.org/10.4000/diacronie.3152 


\section{RESEÑA:}

\section{Julio PONCE ALBERCA, Gibraltar y la Guerra} Civil Española. Una neutralidad singular, Sevilla, Secretariado de Publicaciones de la Universidad de Sevilla, 2009, 248 pp.

por Rodrigo GONZÁLEZ MARTÍN *

55 Una farsa extremadamente útil”. Así resumía un diplomático británico lo que significaba el Comité de No Intervención constituido en Londres en 1936 para impedir la participación extranjera en la Guerra Civil Española ${ }^{1}$ Tres siglos antes Talleyrand ya había apuntado que la No Intervención suponía "poco más o menos lo mismo que intervención" ${ }^{2}$, y es de sobra conocido que durante el conflicto español Alemania, Italia o Rusia la violaron en numerosas ocasiones. ¿Pero hasta qué punto respetaron la neutralidad los propios británicos, principales impulsores del citado Comité de No Intervención?

Julio Ponce Alberca (Sevilla, 1964) es actualmente profesor titular de Historia Contemporánea de la Universidad de Sevilla. Es autor de un importante número de libros, artículos y capítulos de obras colectivas de diversa temática, destacando los dedicados al estudio de las instituciones políticas andaluzas (en los ámbitos regional, provincial y local) desde la dictadura de Primo de Rivera hasta la Transición a la

\footnotetext{
1 TUSELL GÓMEZ, Javier, Vivir en guerra. Historia ilustrada. España 1936-1939, Madrid, Sílex, 2003, p. 85.

2 RAMÓN CHORNET, Consuelo, ¿Violencia necesaria?, Madrid, Trotta, 1995, p. 17.
} 
democracia. La obra que nos presenta es la culminación de una línea de investigación que abrió hace ya algunos años y cuyos frutos han ido viendo la luz de forma parcial en artículos como "La guerra civil española y Gibraltar. Los refugiados españoles en el Peñón"3 o "Andalucía, Gibraltar y la guerra civil”4 y en ponencias como "Diplomacia y comercio a favor de Franco: Gibraltar en la guerra civil española”, presentada en el Congreso Internacional sobre la Guerra Civil Española celebrado en Madrid en 20065.

Gibraltar y la guerra civil española. Una neutralidad singular es el número catorce de la interesante colección "Divulgación Científica" puesta en marcha por la Universidad de Sevilla en 2003. Prologada por el catedrático de Historia Moderna y Contemporánea de España de la Universidad de Sevilla Rafael Sánchez Mantero, la obra estudia la historia de la Roca en los años de la contienda civil, desvelando el importante papel que jugó dentro de la cuestionable política de No Intervención británica. Por increíble que parezca -habida cuenta de la proliferación de investigaciones sobre la Guerra Civil Española en las últimas décadas-, este tema no se había analizado de forma sistemática y global antes de la publicación de este libro, aunque sí había habido algunas aportaciones tangenciales o referentes a aspectos muy concretos de la historia del enclave durante el mencionado período. Desde una perspectiva más amplia es necesario advertir que la historiografía española sobre Gibraltar ha pecado tradicionalmente de falta de objetividad y que sólo en los últimos años la colonia ha empezado a ser objeto de estudios históricos rigurosos en nuestro país -gracias en buena medida a contemporaneístas de la Universidad de Sevilla-.

El libro de Ponce Alberca consta de un prólogo, una introducción, cuatro capítulos divididos a su vez en varios subcapítulos- y unas reflexiones finales, respondiendo la división en capítulos a un criterio fundamentalmente temporal, acorde con el propio desarrollo de la Guerra Civil, y los subcapítulos a un criterio temático.

En la introducción el autor ofrece una caracterización general de Gibraltar y de su importancia en el marco de las relaciones entre España y Gran Bretaña. Orgullo británico y afrenta permanente para los españoles, durante la mayor parte de la época contemporánea la Roca ha sido un enclave militarizado con una función esencialmente estratégica: posibilitar a la Royal Navy el control del Mediterráneo. Aunque España nunca ha dejado de reclamar su devolución -postura defendida también por algunos

\footnotetext{
3 PONCE ALBERCA, Julio, «La Guerra Civil Española y Gibraltar. Los Refugiados Españoles en el Peñón», Almoraima. Revista de Estudios Campogibraltareños, no 25, 2001, pp. 387-402.

4 PONCE ALBERCA, Julio, «Andalucía, Gibraltar y la guerra civil», Andalucía en la Historia, no 15, 2007, pp. 77-82.

${ }^{5}$ URL: < http://personal.us.es/jponce/uploads/CV/cvn.pdf > [13/05/2011],

URL: < http://investigacion.us.es/sisius/sis_showpub.php?idpers=4651 >[13/05/2010].
} 
sectores británicos- y esto ha causado algunas fricciones entre los dos países, lo cierto es que más allá del juego de intereses nacionales la colonia ha mantenido generalmente unas relaciones fluidas con su entorno que han resultado beneficiosas para ambas partes.

El primer capítulo del libro, titulado "Las relaciones entre Gran Bretaña y España”, analiza a través de cinco subapartados el lugar ocupado por Gibraltar en la política exterior española $\mathrm{y}$ en las relaciones hispano-británicas, las características socioeconómicas del Peñón y la influencia que tuvo en el enclave y en la política británica la proclamación y el propio devenir de la II República Española. En el primer tercio del siglo XX España era un país de segunda o tercera fila, con escasa autonomía y una posición estratégica que lo colocaba en el punto de mira de las grandes potencias europeas. Aunque nunca dejó de reclamar la devolución de Gibraltar y tampoco faltaron propuestas de canje del enclave por Ceuta o las Chafarinas -basadas en la vulnerabilidad del Peñón por tierra-, la propia debilidad del país, unida al simbolismo y a la importancia estratégica que la Roca seguía teniendo para los británicos, frustraron cualquier pretensión española en este sentido. En cualquier caso, durante todo este período las relaciones entre España y Gran Bretaña estuvieron presididas por la normalidad y el mutuo entendimiento.

En la década de 1930 Gibraltar era un enclave esencialmente militar y comercial que empezaba a remontar después de experimentar una notable recesión en los años veinte. Dentro de su función comercial destacaban el abastecimiento de carbón y las actividades ilegales como el contrabando (especialmente importante fue el de tabaco) o el tráfico de capitales. Desde España se suministraban a la colonia británica víveres y mano de obra poco especializada, lo que unido a la participación de españoles en las actividades comerciales gibraltareñas servía para dinamizar enormemente la economía de la comarca gaditana del Campo de Gibraltar. En realidad los vínculos entre la Roca y Andalucía eran muchos y muy fuertes, no sólo a nivel económico sino también social, cultural y afectivo.

En el Peñón la vida cotidiana se caracterizaba por la tranquilidad. Los gibraltareños eran una población sumisa y poco problemática para un gobierno británico que apenas les reconocía derechos políticos y que descargaba en última instancia todos los poderes en el gobernador militar. Por supuesto esto no quiere decir que la gibraltareña fuese una sociedad homogénea, y de hecho en su seno había notables diferencias ideológicas (que se traducían en periódicos de diversas tendencias), religiosas (si bien es cierto que la mayoría de los gibraltareños eran católicos) y económicas. 
La proclamación en abril de 1931 de la II República Española produjo cierta inquietud en los sectores conservadores británicos, pero no tuvo una influencia reseñable en las relaciones entre ambos países. España seguía siendo subsidiaria de Francia y de Gran Bretaña, que tenían fuertes inversiones en la Península, y apenas le quedaba espacio para una política de gestos. Si a esto le añadimos la ausencia de una política exterior clara, consecuencia en buena medida de los continuos cambios de gobierno de la etapa republicana, huelga decir que cualquier pretensión de recuperar Gibraltar siguió siendo utópica.

La antipatía de Gran Bretaña por la II República, que se basaba en el miedo al comunismo y a la posible lesión de los intereses británicos en España, se acrecentó con la victoria electoral del Frente Popular en 1936. A Gibraltar, tantas veces lugar de acogida de refugiados españoles, empezaron a llegar entonces conservadores bien posicionados (comerciantes, políticos, propietarios) que temían el estallido de una revolución. Estos asilados, que contaban con la simpatía de las autoridades y las élites gibraltareñas, encontraron en el Peñón un ambiente propicio para conspirar de cara a un golpe de Estado de signo derechista cuya inminencia conocía ya el gobierno londinense.

Esbozados los antecedentes históricos y perfilados algunos puntos esenciales para entender el papel de Gibraltar durante la Guerra Civil Española, el profesor Ponce entra de lleno en el análisis del período bélico, dedicando el segundo capítulo de su obra a "El impacto inicial del conflicto". A lo largo de unas sesenta páginas se informa al lector de los primeros combates navales en la zona del Estrecho y se analizan el posicionamiento de Gran Bretaña frente a la conflagración y su repercusión en un Gibraltar cada vez más lleno de refugiados y destinado a jugar un papel crucial en la configuración de la política exterior británica y en lo que respecta a aspectos clave de la guerra como los flujos de información y de suministros.

Es sabido que al iniciarse la contienda la República disfrutaba de una apreciable superioridad en el mar, pero la descoordinación, la falta de planificación y el establecimiento por parte del bando sublevado de un puente aéreo entre África y España -con ayuda alemana-, hicieron que fracase a la hora de bloquear el Estrecho de Gibraltar. Julio Ponce va un paso más allá para desvelar que los británicos, en gran medida desde Gibraltar, contribuyeron también a este fracaso imponiendo a la flota republicana todo tipo de trabas para repostar y abastecerse y facilitando al mismo tiempo ayudas, suministros e información a los golpistas.

En Gibraltar los republicanos contaban con las simpatías de los sectores obreros, pero el gobernador Harington y las élites de la Roca (como la mayor parte de la élite 
británica relacionada con España) confraternizaban con los sublevados. A sus ojos, la mal llamada "España nacional" representaba orden y seguridad para los intereses anglosajones en la Península. En los primeros momentos del conflicto las principales preocupaciones de Harington fueron la evacuación de súbditos británicos de España y la gestión de la llegada masiva de refugiados españoles a la colonia. Y es que pocos meses después de iniciarse la conflagración ya había en Gibraltar varios miles de refugiados, mayoritariamente de izquierdas (entre ellos, un colectivo importante de masones de logias del Campo de Gibraltar), que era necesario evacuar rápidamente por cuanto constituían no solo una potencial fuente de conflictos internos sino también un foco de insalubridad a causa de las penosas condiciones en que se alojaban.

En otro orden de cosas, no tardaría en quedar claro que la situación internacional iba a favorecer a los rebeldes. La constitución, a iniciativa británica, de un Comité de No Intervención destinado teóricamente a garantizar que la guerra no saliese de las fronteras españolas y a vetar la llegada de ayuda internacional a ambos bandos, fue en la práctica una escenificación del abandono de la República por parte de las potencias occidentales. Bajo esta fachada Gran Bretaña pretendía asegurar sus intereses e influencia en España, y a tal efecto no dudó en sumarse, aunque de forma más taimada, a los apoyos que ya prestaban a los sublevados Alemania e Italia.

La realidad diplomática de ambos bandos es esclarecedora. Las cancillerías europeas pusieron numerosas trabas a unos representantes del gobierno legítimo de España que en muchas ocasiones ni siquiera eran diplomáticos profesionales, ya que la mayor parte de éstos acabó decantándose por el bando sublevado. En el caso concreto de Gibraltar, el consulado republicano atravesó por un período de marcada inestabilidad al iniciarse la contienda y tardó meses en ser reconocido por las autoridades británicas. Su labor en la Roca fue además mucho menos fructífera que la desempeñada por los agentes oficiosos de Franco, que incluso lograron suministros de petróleo. En contraprestación, los rebeldes garantizaron a Gibraltar alimentos frescos y mano de obra.

En relación con la dimensión internacional del conflicto debe tenerse en cuenta también el papel jugado por la información en general y, muy particularmente, por la prensa. A través de ella ambos bandos trataron de canalizar ideas e influir en las potencias extranjeras, cuyos gobiernos y ciudadanos estaban muy interesados, por motivos bien distintos, en el conflicto español. En este contexto Gibraltar se convirtió en una plataforma privilegiada para observar la guerra y obtener información fidedigna, algo que sería aprovechado por informadores, espías -operaron en la Roca varias redes de espionaje franquistas y republicanas, demostrándose las primeras mucho más efectivas- $\mathrm{y}$ periodistas. 
El tercer capítulo se titula "Una guerra estabilizada" y se ocupa aproximadamente de los años 1937 y 1938. Estudia el desarrollo de algunos asuntos ya planteados en el capítulo previo, como el de los refugiados, el de la representación diplomática del bando franquista en la Roca o el de la ayuda económica prestada por Gran Bretaña a los sublevados. La parte final del capítulo analiza la aparición de tensiones entre la España de Franco y los británicos a medida que se fue acercando el final del conflicto.

El curso de la guerra sonreía a Franco, lo que unido a sus buenas relaciones con Gran Bretaña condujo al intercambio de representantes oficiosos entre Burgos y Londres en noviembre de 1937. En Gibraltar se instaló un consulado franquista de facto encabezado por el monárquico Luciano López Ferrer, que disponiendo de dinero y apoyos desplegó una actividad más intensa y provechosa que el consulado republicano.

Mucho más determinante que el mentado reconocimiento oficioso fue en cualquier caso la ayuda económica que los británicos prestaron a Franco, a quien exportaron grandes cantidades de carbón, estaño y manufacturas. Desde Gibraltar, y sin que las autoridades republicanas pudiesen hacer nada para evitarlo, la no intervención fue violada sistemáticamente para proveer a la zona franquista de combustible y suministros que llegaban a la colonia en buques ingleses, estadounidenses, alemanes, italianos y portugueses.

Aunque en 1937 la actividad bélica en las inmediaciones del Peñón descendió drásticamente, Gibraltar siguió siendo lugar de paso y de asilo, vía de evacuación de huidos, punto de enlace de correos y cablegramas, etc. En 1937 y 1938 el alto número de refugiados continuó representando un serio problema, pues no dejaban espacio para los propios empleados civiles y militares que llegaban a la Roca y, siendo mayoritariamente republicanos, enturbiaban las relaciones entre Gran Bretaña y los sublevados. A pesar de las sucesivas evacuaciones y de la implementación de férreos controles para evitar la entrada de nuevos refugiados, sólo en octubre de 1938 logró Harington, mediante una gran evacuación, dejar la cifra de asilados dentro de lo asumible para las autoridades del Peñón. Fue una de las últimas cosas que hizo como gobernador, pues a finales de ese año lo sustituyó en el puesto E. Ironside, que concentraría sus esfuerzos en el fortalecimiento militar de la Roca en el marco de una situación internacional cada vez más hostil y de un enfriamiento de las buenas relaciones con Franco. En efecto, ya a lo largo de 1938 hubo algunas fricciones entre Gran Bretaña y la España franquista ${ }^{6}$, cuyo protofascismo era visto además con cierta

\footnotetext{
${ }^{6}$ Queipo de Llano reclamó Gibraltar en un discurso, Gran Bretaña invadió aguas no contempladas en ningún acuerdo para construir el nuevo aeropuerto de Gibraltar, etc.
} 
preocupación desde Londres. Ello no fue suficiente, en cualquier caso, para quebrantar la determinación británica de favorecer la victoria de los sublevados.

El cuarto y último capítulo del libro, "El final de un conflicto", explora las relaciones entre la España franquista y Gran Bretaña desde los últimos compases de la Guerra Civil hasta la II Guerra Mundial. En febrero de 1939 Gran Bretaña reconoció plenamente a la España de Franco, que en poco más de un mes consumó su victoria sobre la República. Las propias características ideológicas del nuevo régimen español hicieron que arreciase la secular reivindicación de Gibraltar, lo que unido al acercamiento entre Franco y las potencias fascistas agravó el deterioro del otrora buen entendimiento hispano-británico. Dentro de Gibraltar las relaciones ente el cónsul franquista y el gobernador británico también empeoraron, debido tanto a una falta de afinidad personal entre ambos como a la existencia de puntos concretos de fricción: presencia residual de refugiados republicanos en la Roca, espionaje franquista, etc.

Durante la primera fase de la II Guerra Mundial los recelos aumentaron. España se permitió algunos gestos de protesta por Gibraltar, llegó a pergeñar planes para invadir el Peñón y favoreció el espionaje del Eje y el hostigamiento italiano a la Roca. No obstante, estos no fueron motivos suficientes para provocar una ruptura abierta con Gran Bretaña, que se marcó como objetivo mantener a España fuera del conflicto.

La obra cierra con unas reflexiones finales en las que el autor aporta algunas pinceladas sobre el devenir de las relaciones hispano-británicas una vez concluida la II Guerra Mundial. Unas relaciones que estuvieron presididas por la ambigüedad, con continuos tiras y aflojas y momentos de mayor tensión como los que desembocaron en el cierre de la verja de Gibraltar entre 1969 y 1982. Y unas relaciones condicionadas también por la persistencia de la reclamación española del Peñón, que llevó a la dictadura a falsear la Historia para asegurar que la colonia había ayudado a la República durante la Guerra Civil.

Gibraltar y la guerra civil española. Una neutralidad singular es un libro de Historia bien articulado, coherente y de una objetividad encomiable, pergeñado a partir de un manejo intenso y certero de fuentes documentales, hemerográficas y bibliográficas inglesas, gibraltareñas y españolas. La edición, bastante cuidada, añade al texto la inexcusable tabla de contenidos, un índice onomástico, una breve cronología donde se consignan los principales acontecimientos recogidos en el libro y un amplio apartado con las fuentes y la bibliografía consultadas. En la parte central de la obra se incluye además un apéndice gráfico que sabe a poco -probablemente debido a exigencias editoriales- y en el que a nuestro entender habría sido interesante incluir un mapa. 
El solo hecho de venir a enjugar la desatención historiográfica que se había posado sobre un tema de tanto interés como el papel de Gibraltar y de los gibraltareños en la Guerra Civil Española justificaría sin duda la obra presentada por Julio Ponce. Pero lo cierto es que los méritos del libro exceden en mucho la mera oportunidad de su temática. El historiador sevillano ha conformado un texto en el que el rigor científico convive con un estilo y una estructura sencillos y asequibles, algo tan complejo como deseable en un momento en que la Historia necesita quizá más que nunca aprender a conectar con el conjunto de la sociedad. En esta línea creemos que uno de los puntos fuertes del libro es su estupenda contextualización histórica, política y social, que permite al lector una comprensión global de lo sucedido en Gibraltar entre 1936 y 1939 mediante su inclusión en un marco temporal y geográfico mucho más amplio. Finalmente, a través del estudio del caso gibraltareño -que demuestra ser perfecto para tomar el pulso a las relaciones hispano-británicas-, Julio Ponce aporta nuevos y contundentes datos sobre el apoyo de Gran Bretaña al bando sublevado.

Así las cosas, sólo nos queda pedirle al autor que prosiga sus investigaciones sobre este particular, pues consideramos que aún podrá aportar más datos de interés a través de la consulta sistemática de la prensa republicana de la época o del trabajo con fuentes orales, que quizá arrojen algo de luz sobre, por ejemplo, la vida cotidiana en el enclave durante los años de la Guerra Civil. Sería igualmente interesante que el profesor Ponce extendiese su estudio al período de la II Guerra Mundial, abordado ya someramente en este mismo libro. 


\section{${ }^{*}$ El autor}

Rodrigo González Martín es licenciado en Historia por la Universidad de Valladolid (2009), en la que ha realizado también el Máster "Europa y el Mundo Atlántico. Poder, Cultura y Sociedad" (2010). Ha investigado acerca de temas tan dispares como la historia de la Arqueología en la provincia de Valladolid o el conflicto checheno, y actualmente está realizando su tesis doctoral sobre la transición democrática española.

URL: < http://studistorici.com/progett/autori/\#GonzálezMartín >

\section{Per citare questo articolo:}

GONZÁLEZ MARTíN, Rodrigo, «Reseña: Julio PONCE ALBERCA, Gibraltar y la Guerra Civil Española. Una neutralidad singular, Sevilla, Secretariado de Publicaciones de la Universidad de Sevilla, 2009, 248 pp.», Diacronie. Studi di Storia Contemporanea: Spagna Anno Zero: la guerra come soluzione, 29/07/2011,

URL:<http://www.studistorici.com/2011/071/29/gonzalezmartin_numero_7>

Diacronie Studi di Storia Contemporanea $\beta$ www.diacronie.it

Risorsa digitale indipendente a carattere storiografico. Uscita trimestrale.

redazione.diacronie@hotmail.it

Comitato di redazione: Marco Abram - Giampaolo Amodei - Jacopo Bassi - Luca Bufarale - Alessandro Cattunar - Alice De Rensis Barbara Galimberti - Deborah Paci - Fausto Pietrancosta - Martina Sanna - Matteo Tomasoni - Luca Zuccolo

Diritti: gli articoli di Diacronie. Studi di Storia Contemporanea sono pubblicati sotto licenza Creative Commons 2.5

Possono essere riprodotti a patto di non modificarne i contenuti e di non usarli per fini commerciali. La citazione di

estratti è comunque sempre autorizzata, nei limiti previsti dalla legge. 